Article

\title{
Estimation of Travel Demand for Bangkok-Chiang Mai Hyperloop Using Traveler Surveys
}

\author{
Paras Agrawal *D and Surachet Pravinvongvuth \\ Transportation Engineering, School of Engineering and Technology, Asian Institute of Technology, \\ Klong Luang 12120, Thailand; spravinvongvuth@ait.ac.th \\ * Correspondence: agrawal.paras94@gmail.com; Tel.: +91-8586820834
}

Citation: Agrawal, P.;

Pravinvongvuth, S. Estimation of Travel Demand for Bangkok-Chiang Mai Hyperloop Using Traveler Surveys. Sustainability 2021, 13, 14037. https://doi.org/10.3390/ su132414037

Academic Editor: Armando Cartenì

Received: 15 October 2021

Accepted: 16 December 2021

Published: 20 December 2021

Publisher's Note: MDPI stays neutral with regard to jurisdictional claims in published maps and institutional affiliations.

Copyright: (c) 2021 by the authors. Licensee MDPI, Basel, Switzerland. This article is an open access article distributed under the terms and conditions of the Creative Commons Attribution (CC BY) license (https:/ / creativecommons.org/licenses/by/ $4.0 /)$.

\begin{abstract}
Hyperloop, projected as fast and efficient, and envisaged as the future of high-speed transportation, does not have much published information about its demand estimation. This paper aims to estimate the willingness of air and car passengers to shift to hyperloop. A nested logit model was used to analyze stated preference data gathered from the air and car travelers along the Bangkok-Chiang Mai sector in Thailand. The variables contributing the most to the modal shift towards hyperloop are total travel cost, total travel time, monthly income, gender, education level, bearer of trip expenses, and number of trips in the last 6 months and duration of stay at the destination. The highest value of elasticity for hyperloop is obtained for the total travel cost followed by total travel time and monthly income. It is concluded that hyperloop will be the predominant mode of transportation between the Bangkok-Chiang Mai sectors with a modal share of almost 50\% by the year 2025. Survey results also revealed that the preferences of the passengers in order of priorities for long distance travel are comfort, low travel cost, less travel time, safety, high frequency of travel mode and low $\mathrm{CO}_{2}$ emission. The main contribution of this paper is to provide an insight on factors that may contribute towards a possible shift in mode from car and air to hyperloop. The study will be beneficial to policy makers in developing a strategy for a more efficient mass transportation system using new and emerging technologies.
\end{abstract}

Keywords: traveler's mode choice; nested logit model; stated preference survey; hyperloop; intercity travel; NLOGIT; Thailand

\section{Introduction}

Bangkok, the capital of Thailand, is among one of the well-developed cities in the Asian region. With the economic development of the Bangkok region, the vehicle ownership in the region has increased significantly in last two decades, resulting in traffic congestion. Bangkok is ranked 11th among the cities that face the worst traffic congestions around the globe [1]. Chiang Mai is among the top three travel destinations in Thailand along with Bangkok and Phuket. Being a regional economic and cultural/heritage hub, Chiang Mai attracts millions of tourist and business personnel every year. This influx is transforming Chiang Mai into a real estate hub which in turn is making the traffic situation in Chiang Mai worse, day by day [2]. Besides road congestion in its major cities, Thailand also faces congestion at five main airports, namely, Suvarnabhumi, Don Mueang, Phuket, Chiang Mai and Hat Yai airports, as they have already surpassed their capacities.

Location-wise, Bangkok is situated in Central Thailand while Chiang Mai is situated in Northern Thailand. By road both the cities are $695 \mathrm{~km}$ apart. Air, bus, car and rail are the four major modes of transportation between the two cities. As per the 2010 census, the Bangkok metropolitan area had a population of 14.62 million, while the Chiang Mai metropolitan area had nearly 1.73 million people [3]. Annually, about 14.5 million trips are performed between Bangkok and Chiang Mai with majority of the ridership (around 90\%) constituting air and car travelers. 
Passenger cars, freight vehicles and flights are major contributors to greenhouse gas emissions. Even the rail that runs on fossil fuel-based electricity is carbon intensive. In Thailand, the transport sector is one of the major emitters of $\mathrm{CO}_{2}$ along with the power and industrial sector [4,5]. As a result, the government of Thailand targets to reduce greenhouse gas emissions by 2030 to a level of $75 \%$ to $80 \%$, as compared to current levels [6]. The congestion and pollution necessitates exploration of alternate modes of transport, which are more environmental friendly.

Humans have always strived for faster modes of transportation. For viability of any new mode of transportation, an assessment of the shift towards a new mode is essential. Estimating the potential demand for proposed new services also helps the decision makers in creating an equilibrium between the objectives to be fulfilled and stretched public resources. At the same time, the individual's choice to shift to other modes of transport is influenced by factors, such as socioeconomic, trip and mode characteristics, which must be known beforehand to arrive at a comprehensive decision. The main contribution of this paper is to provide an insight on factors that may contribute towards a possible shift in mode from car and air to hyperloop. The study will be beneficial to policy makers in developing a strategy for a more efficient mass transportation system using new and emerging technologies. It may be noted that hyperloop does not have much published information about its demand estimation and this study is first of its kind for hyperloop in Thailand.

The overall aim of this paper is to estimate the travel demand for Bangkok-Chiang Mai hyperloop using traveler surveys. As majority of the ridership (around 90\%) in the corridor is made up of air and car travelers, the Bangkok-Chiang Mai corridor is an ideal section for the hyperloop system. Disaggregate mode choice models were developed based on Stated Preference (SP) data collected via intercept surveys. Due to inability of SP data to represent the initial market shares as observed in the real world, the alternative-specific constants obtained from the model were calibrated using true market shares. The model specification developed considers level-of-service variables, socio-economic variables and trip-related variables in utility function specifications. The final calibrated NL model was used to obtain direct and cross elasticities, value of travel time savings and estimated ridership for the year 2020 and 2025.

\section{Literature Review}

Hyperloop, also dubbed as the "fifth mode of transportation", was conceptualized and proposed as a very high speed, fixed-guideway intercity surface transportation, using capsule-like vehicles operating in sealed low-pressure tubes capable of transporting both passenger and freight, nearly at the speed of sound [7,8]. Hyperloop is proposed as an alternative to short and medium haul flights as it aims to reduce inefficiencies related to air travel such as checking in, waiting, boarding and departing $[9,10]$. Hyperloop is also intended to be an environmentally friendly mode of transport powered through renewable energy [11]. In addition, as the capsules move through low pressure tubes, less noise will be generated compared to HSR [12].

In 2018, the Japan International Cooperation Agency (JICA) published the results of a feasibility study considering a future Bangkok-Chiang Mai High-Speed Rail (HSR) line using Shinkansen technology. The study concluded that the line would run at a loss, mainly due to a lack of ridership in the corridor [13]. In 2019, TransPod (a Canadian company designing ultra-high-speed transportation systems) published a preliminary study on the implementation of a TransPod hyperloop line in Thailand. The analysis conducted in this report demonstrated that implementing the hyperloop technology in Thailand could have significant positive impacts for the country as a whole. The substantial travel time savings provided by hyperloop technology will profoundly impact the way people travel in the corridor and act as a catalyst for the expected economic growth. The study carried out by TransPod, however, was only based on secondary data and lacked any primary inputs on the traveler's preference of mode choice [14]. 
To investigate a traveler's preference of mode choice and behavior, questionnaire surveys are performed. Usually surveys are conducted based on Revealed Preference (RP) data, Stated Preference (SP) data or a combination of both. SP Surveys are extensively used in the field of discrete choice modeling, particularly for determining the potential modal split due to a hypothetical mode of transport. Lubis and Farda [15] developed an SP survey to estimate the demand for Jakarta-Surabaya HSR. They used fractional factorial design for three attributes - travel time, tariff and frequency. Roman et al. [16] analyzed the impact of HSR on competing modes in the Madrid-Zaragoza-Barcelona corridor using both RP and SP techniques. Sperry et al. [17] used different experimental designs for SP questions and suggested the use of visualizations for SP surveys for transport services that currently do not exist in order to support respondents' decision-making process.

Mode choice is affected by various attributes. Questionnaires are designed to explore the respondent's data, which usually includes socioeconomic characteristics, trip characteristics, mode choice preference, attitudinal information and diagnostic questions, in order to assess the understanding of the questionnaire by the individual [18-21]. Intercity travel, travel time, travel cost and service frequency are considered to have the most profound influence on mode choice [15]. Occupation, household income, education and purpose of the trip are also key factors in determining the competition between alternatives for intercity travel [22]. Attributes such as nationality, privacy, convenience, comfort, safety and weather conditions can also be considered, along with socio-economic, trip and travel mode characteristics to estimate potential modal split [23]. However, it is not advisable to include attributes such as privacy, comfort, convenience and reliability at the planning stage, due to insignificant improvements in mode choice models and difficulty in obtaining such perceptions [24].

Mode choice is an indispensable part of the transportation planning process and plays a vital role in policy making [25]. It is used to analyze and predict the choices that a person or group of persons make in selecting a mode of transport. Data can be collected at an aggregate or a disaggregate level, but usually disaggregate models are preferred as they are based on individual level data and are more efficient in terms of model reliability [26-29]. Park and Ha [30] analyzed modal shares between air travel and HSR by using the binary logit technique and concluded that the elasticity of travel demand is larger for trip cost in comparison to travel time and travel frequency. Researchers in the past have developed a multinomial logit model for mode choices among car, air and HSR travelers with different fare levels and concluded that users traversing long-distances and having high-incomes prefer HSR and air modes; however, when the users are travelling in larger groups, the preference shifts to a cheaper mode [31-33]. Bhat [34] used a multinomial logit model to determine the mode shares among air, HSR, and car modes and found that high-income users, men and single travelers prefer air modes while women and groups favor HSR.

Based on studies conducted in past, it appears that the attributes that could affect the mode choice preference are the total travel time, total travel cost, service frequency, monthly income, gender, age, education level, bearer of trip expenses, trip frequency, duration of stay and travel group size. For multimodal corridors, the multinomial logit and nested logit models were most widely used.

\section{Materials and Methods}

\subsection{Theoretical Framework}

Discrete choice models are usually derived under an assumption of utility-maximizing behavior by the decision maker $[35,36]$. The overall utility associated with the ith alternative can be expressed in terms of observed utility $\left(\mathrm{V}_{\mathrm{i}}\right)$ and random error $\left(\varepsilon_{\mathrm{i}}\right)$ given by the equation:

$$
\mathrm{U}_{\mathrm{i}}=\mathrm{V}_{\mathrm{i}}+\varepsilon_{\mathrm{i}}
$$


This observed utility can be expressed as a linear expression of the set of attributes (say K) of the respective alternative given by the equation:

$$
V_{i}=\beta_{0 i}+\beta_{1 i} f\left(X_{1 i}\right)+\beta_{2 i} f\left(X_{2 i}\right)+\ldots+\beta_{K i} f\left(X_{K i}\right)
$$

where $\beta_{1 \mathrm{i}}$ is weight-associated with attribute $X_{1}$ and alternative $i, \beta_{0 \mathrm{i}}$ is an alternate specific constant representing the average role of the unobserved utility and $f(\ldots)$ represents the ways in which an attribute enters the utility function.

The probability that an alternative $i$ will be selected by an individual depends on whether the probability of the utility associated with $i$ is greater than or equal to the utility of alternative $\mathrm{j}$ in a set of $\mathrm{j}=1, \ldots, \mathrm{i}, \ldots, \mathrm{J}$ alternatives, as shown by equation:

$$
\operatorname{Prob}_{\mathrm{i}}=\operatorname{Prob}\left(\mathrm{U}_{\mathrm{i}} \geq \mathrm{U}_{\mathrm{j}}\right)
$$

There are a variety of functional forms that can be used for discrete choice. The simplest and most popular is the multinomial logit (MNL) model given by McFadden in 1975. This MNL model is based on the assumptions that error components are Gumbel (EV1) distributed and identically and independently distributed (IID) among the alternatives and individuals. An important property of the MNL model is that the ratio of choice probabilities of a pair of alternatives is independent from other alternatives, i.e., the independent from irrelevant alternatives (IIA) property [37]. The MNL relates the probability of decision maker $\left(\mathrm{P}_{\mathrm{i}}\right)$ to choose an alternative "I" $(\mathrm{i}=1,2, \ldots, \mathrm{j})$ from a set of alternatives $(\mathrm{J})$ by the equation:

$$
P_{i}=\frac{\exp V_{i}}{\sum_{j=1}^{J} \exp V_{j}}
$$

where $V_{i}$ and $V_{j}$ are systematic components of the utility of alternatives $i$ and $j$.

MNL models have faced criticism because of their IID/IIA assumption. To counter this, nested logit (NL) models were developed, which partially relaxes the IID/IIA assumption of the MNL models. The NL model "nests" together the alternatives that share some common traits [38]. Assuming that the set of alternatives i are divided into $\mathrm{K}$ non- overlapping sets $\left(B_{1}, B_{2}, \ldots, B_{k}\right)$, the observed utility $\left(V_{i}\right)$ can be decomposed into two parts: one that is constant for all alternatives within the nest $\left(\mathrm{W}_{\mathrm{k}}\right)$ and a second that varies over the alternatives within the nest $\left(\mathrm{Y}_{\mathrm{i}}\right)$. The overall utility associated with the ith alternative is given by the equation:

$$
\mathrm{U}_{\mathrm{i}}=\mathrm{W}_{\mathrm{k}}+\mathrm{Y}_{\mathrm{i}}+\varepsilon_{\mathrm{i}}
$$

For two-level NL models, the probability of selecting an alternative at a lower level is conditional on the probability of selecting the corresponding higher level. The probability of selecting the highest level is not conditional on any other choice and is thus referred as marginal probability [39]. Therefore, in the case of NL models, the probability of selecting an alternative $i \in B_{k}$ is given by the equation:

$$
P_{i}=P_{i \mid B_{k}} P_{B_{k}}
$$

where $P_{i} \mid B_{k}$ is the conditional probability of selecting alternative $i$, given that the nest $B_{k}$ is chosen and $P_{B k}$ is the marginal probability of selecting the nest $B_{k}$.

The conditional and marginal probabilities, respectively, can be expressed by the equations:

$$
\begin{gathered}
\mathrm{P}_{\mathrm{i} \mid \mathrm{B}_{\mathrm{k}}}=\frac{\exp \left(\mathrm{Y}_{\mathrm{i}} / \lambda_{\mathrm{k}}\right)}{\sum_{\mathrm{j} \in \mathrm{B}_{\mathrm{k}}} \exp \left(\mathrm{Y}_{\mathrm{j}} / \lambda_{\mathrm{k}}\right)} \\
\mathrm{P}_{\mathrm{B}_{\mathrm{k}}}=\frac{\exp \left(\mathrm{W}_{\mathrm{k}}+\lambda_{\mathrm{k}} \mathrm{I}_{\mathrm{k}}\right)}{\sum_{\mathrm{l}=1}^{\mathrm{K}} \exp \left(\mathrm{W}_{\mathrm{l}}+\lambda_{\mathrm{l}} \mathrm{I}_{\mathrm{l}}\right)}
\end{gathered}
$$


where $I_{k}$ is the Inclusive Value (IV), which is the natural logarithm of the denominator of the MNL model corresponding to the alternatives within a nest and $\lambda$ is the IV parameter.

\subsection{The Data}

\subsubsection{Secondary Data}

Data related to the number of trips made in the Bangkok-Chiang Mai sector in 2017 and 2018 corresponding to air, bus and rail transport were obtained from the airports of Thailand (AOT), Department of Land Transport (DLT) and State Railway of Thailand (SRL), respectively. Data related to the number of trips made by car users based on the National Model were obtained from the Office of Transport and Traffic Policy and Planning (OTP). Table 1 summarizes the number of trips made in the Bangkok-Chiang Mai sector and the corresponding modal split for the years 2017 and 2018.

Table 1. Number of trips in Bangkok-Chiang Mai corridor for 2017 and 2018.

\begin{tabular}{|c|c|c|c|c|c|}
\hline \multirow{2}{*}{ Mode } & \multicolumn{2}{|c|}{2017} & \multicolumn{2}{|c|}{2018} & \multirow{2}{*}{$\%$ Change } \\
\hline & Trips & $\%$ & Trips & $\%$ & \\
\hline Car & $6,328,370$ & 44.90 & $6,593,214$ & 45.31 & 4.19 \\
\hline Bus & $1,227,336$ & 8.71 & $1,134,416$ & 7.80 & -7.57 \\
\hline Rail & 435,056 & 3.09 & 355,247 & 2.44 & -18.34 \\
\hline Air & $6,103,520$ & 43.30 & $6,467,212$ & 44.45 & 5.96 \\
\hline Total & $14,094,282$ & 100.00 & $14,550,089$ & 100.00 & 3.23 \\
\hline
\end{tabular}

\subsubsection{Primary Data}

To obtain the data from existing travelers in the Bangkok-Chiang Mai corridor, a SP survey was undertaken. Respondents were asked about their modal preference between car, air and hyperloop in a hypothetical situation created due to the introduction of hyperloop as a mode of transport in the Bangkok-Chiang Mai sector. Bus and rail passengers were not considered, as their combined trip share was only about $10 \%$ of the total trips for the year 2018. The questionnaire used for the survey was divided into three sections. The first part was designed to collect information on the respondents' socio-economic characteristics and their preferred considerations in terms of safety, comfort, low travel cost, less travel time, high frequency and low $\mathrm{CO}_{2}$ emission for intercity travel. The second part was designed to explore the respondents' current trip characteristics. The last part of the questionnaire consisted of the SP travel choice. For the SP survey, two attributes, total travel time and total travel cost were considered for all the three alternatives (car, air and hyperloop), while a third attribute of service frequency was also used for air and hyperloop. As the three attribute levels provide a good approximation of their underlying utility function, each attribute was further characterized by three attribute levels. As the possible combinations of choice sets was running into the thousands, the total number of choice sets required for the SP survey were determined through an experimental design. A fractional factorial design considering only the main effects was generated using SPSS statistical software [35], so that the orthogonality is maintained between the attributes and thus a manageable choice set of 27 options was generated. As presenting 27 choice sets to a single respondent was not deemed practical, a blocking variable was also used to divide the choice sets in three blocks with 9 choice sets each. This was done with the perspective that a respondent who is in transit may not like sparing more than 8-10 min for the survey [40].

The distance by road between Bangkok and Chiang Mai is about $695 \mathrm{~km}$; with an average speed of $100 \mathrm{kmph}$, it will require a minimum of $7 \mathrm{~h}$ to travel between the two cities. This was considered to be the minimum amount of time required to travel between the two cities by car. As per Google Maps, the average travel time between the two cities is about $8.5 \mathrm{~h}$; therefore, this was considered to be the second option. Accordingly, the third travel time option was kept at $10 \mathrm{~h}$. As far as travel cost is concerned, considering the average fuel price for the year 2019 to be 27.29 THB/liter [41], with an average fuel 
consumption of $8.0 \mathrm{Lge} / 100 \mathrm{~km}$ [42], the cost of travel by car between Bangkok and Chiang Mai works out to be approximately 1600 THB. Considering the lowest fuel price (Gasohol 95-E85 at 20.14 THB/liter), the approximate travel cost between Bangkok and Chiang Mai works out to be $1200 \mathrm{THB}$; with highest fuel price (ULG $95 \mathrm{RON}$ at $35.36 \mathrm{THB} /$ liter), the approximate travel expense for the same sector works out to be approximately $2000 \mathrm{THB}$. As the cars used for traveling in the corridor are personal cars, the option for frequency was not applicable.

The flying time between Bangkok and Chiang Mai sector is $1 \mathrm{~h} 15 \mathrm{~min}$. As per the directives, domestic passengers are advised to report at the airport $2 \mathrm{~h}$ before the departure of the flight and the boarding counter closes $45 \mathrm{~min}$ before the departure of the flight. Hence, the minimum time for boarding the flight was considered to be $45 \mathrm{~min}$. The deboarding time was kept at $15 \mathrm{~min}$. Keeping the time to travel to/from the airport at approximately $45 \mathrm{~min}$, the minimum total travel time for air travel was kept at $180 \mathrm{~min}$, i.e., $3 \mathrm{~h}$. The second option for the travel time at $4.5 \mathrm{~h}$ was worked out with a reporting time of $2 \mathrm{~h}$ and deboarding time of $30 \mathrm{~min}$. The mid value of $3 \mathrm{~h}$ and $4.5 \mathrm{~h}$ was considered the third option. As far as travel cost is concerned, in view of the "differential" pricing followed by airlines as well as the pricing as indicated on various sites, the travel cost attribute levels were kept at 1000 THB, 1750 THB and 2500 THB. During peak hours, the flights between Bangkok and Chiang Mai are available in 10 min intervals and throughout the day, on average, the flights are available every half an hour. The frequency of flights was therefore kept accordingly.

The values for the attribute levels of hyperloop were determined from published sources. A study conducted by TransPod in Thailand estimated the travel cost between Bangkok-Chiang Mai sector at 1012 THB, with the travel time including boarding and deboarding at $1 \mathrm{~h} 12 \mathrm{~min}$ (with average travel speed at approximately $680 \mathrm{kmph}$ ) [14]. For formulating the attributes towards travel cost, the lowest value in the case of the hyperloop was kept in line with the cost estimated in the TransPod report, i.e., at 1000 Baht. The progressive increase in the total travel cost was kept the same as that of air. For Hyperloop, the minimum total travel time, including the time for travel in hyperloop (approximately $55 \mathrm{~min}$ at an average speed of $680 \mathrm{kmph}$ ), boarding and deboarding (approximately $20 \mathrm{~min}$ ) and time to travel to/from the hyperloop station (approximately $45 \mathrm{~min}$ ) was kept at $120 \mathrm{~min}$ or $2 \mathrm{~h}$. Two other progressive options towards travel time $(2 \mathrm{~h} 45 \mathrm{~min}$ and $3 \mathrm{~h}$ $30 \mathrm{~min}$ ) with hyperloop were worked out for the approximate average travel speed of $350 \mathrm{kmph}$ and $250 \mathrm{kmph}$, respectively, keeping the boarding/deboarding and time to travel to/from the hyperloop station the same. As per the TransPod report, the hyperloop capsules can conveniently be released at an interval of $80 \mathrm{~s}$ with each carrying approximately 28 to 40 passengers. This means that roughly 5 capsules will carry passengers equal to one Boeing flight (with almost $100 \%$ capacity utilization), which translates to almost $7 \mathrm{~min}$. The minimum frequency value for hyperloop, therefore, was kept at the level of $5 \mathrm{~min}$. The attribute levels used for the development of the SP experimental design are summarized in Table 2.

Table 2. Attribute levels for SP design.

\begin{tabular}{|c|c|c|c|c|}
\hline Attribute & Levels & Car & Airplane & Hyperloop \\
\hline \multirow{3}{*}{ Total travel time (hours) } & 1 & 7 & 3 & 2 \\
\hline & 2 & 8.5 & 3.75 & 2.75 \\
\hline & 3 & 10 & 4.5 & 3.5 \\
\hline \multirow{3}{*}{ Total travel cost (THB) } & 1 & 1200 & 1000 & 1000 \\
\hline & 2 & 1600 & 1750 & 1750 \\
\hline & 3 & 2000 & 2500 & 2500 \\
\hline \multirow{3}{*}{ Service frequency (minutes) } & 1 & - & 10 & 5 \\
\hline & 2 & - & 20 & 10 \\
\hline & 3 & - & 30 & 15 \\
\hline
\end{tabular}


Sample size required for conducting the stated preference survey was determined by using the simple random samples (SRS) technique. Assuming a confidence interval of 95\%, allowable error of 0.05 for the car alternative and modal split corresponding to the year 2018, a minimum sample size of 209 ( 210) was obtained for each car and air alternative.

The questionnaire used for data collection was amended based on the pilot test. Then, a pen- and paper-based survey was conducted for car and air travelers along the Bangkok-Chiang Mai sector at different locations and a total of 420 questionnaires with cogent responses were picked. The survey was conducted in January and February 2020. Car users were interviewed at Highway Police Service Units along the Asian Highway 2 (AH2) - the only highway to connect Bangkok and Chiang Mai. Air travelers were interviewed at Don Mueang International Airport and at Chiang Mai International Airport. Before administering the survey questionnaire, the respondents were asked about their awareness of the hyperloop concept. The respondents who were not aware of this concept were explained in detail about this emerging technology. The information section on hyperloop formed an integral part of the survey questionnaire. The descriptive statistics of the sample is shown in Table 3. The average total travel cost and total travel time for the car respondents was $1837 \mathrm{THB}$ and $8 \mathrm{~h} 45 \mathrm{~min}$, respectively, whereas the average total travel cost and total travel time (from origin to destination) for air respondents was $2015 \mathrm{THB}$ and $3 \mathrm{~h} 54 \mathrm{~min}$, respectively. The average time spent at the airport (boarding and deboarding) and in the flight was $158 \mathrm{~min}(2 \mathrm{~h} 38 \mathrm{~min})$.

Table 3. Descriptive statistics of the sample.

\begin{tabular}{|c|c|c|c|c|c|c|c|}
\hline \multirow{2}{*}{\multicolumn{2}{|c|}{ Characteristics }} & \multicolumn{6}{|c|}{ Quantity (Percentage) } \\
\hline & & \multicolumn{2}{|c|}{ Car } & \multicolumn{2}{|c|}{ Air } & \multicolumn{2}{|c|}{ Total } \\
\hline \multirow{2}{*}{ Gender } & Male & 178 & $(84.76 \%)$ & 90 & $(42.86 \%)$ & 268 & $(63.81 \%)$ \\
\hline & Female & 32 & $(15.24 \%)$ & 120 & $(57.14 \%)$ & 152 & $(36.19 \%)$ \\
\hline \multirow{6}{*}{ Age } & Less than 22 years & 5 & $(2.38 \%)$ & 10 & $(4.76 \%)$ & 15 & $(3.57 \%)$ \\
\hline & 22 to 30 years & 39 & $(18.57 \%)$ & 102 & $(48.57 \%)$ & 141 & $(33.57 \%)$ \\
\hline & 31 to 40 years & 74 & $(35.24 \%)$ & 49 & $(23.33 \%)$ & 123 & $(29.29 \%)$ \\
\hline & 41 to 50 years & 51 & $(24.29 \%)$ & 21 & $(10.00 \%)$ & 72 & $(17.14 \%)$ \\
\hline & 51 to 60 years & 31 & $(14.76 \%)$ & 18 & $(8.57 \%)$ & 49 & $(11.67 \%)$ \\
\hline & Above 60 years & 10 & $(4.76 \%)$ & 10 & $(4.76 \%)$ & 20 & $(4.76 \%)$ \\
\hline \multirow{5}{*}{ Education Level } & Lower than high school & 25 & $(11.90 \%)$ & 2 & $(0.95 \%)$ & 27 & $(6.43 \%)$ \\
\hline & High school or equivalent & 32 & $(15.24 \%)$ & 23 & $(10.95 \%)$ & 55 & $(13.10 \%)$ \\
\hline & Diploma & 25 & $(11.90 \%)$ & 11 & $(5.24 \%)$ & 36 & $(8.57 \%)$ \\
\hline & Bachelor's degree & 108 & $(51.43 \%)$ & 141 & $(67.14 \%)$ & 249 & $(59.29 \%)$ \\
\hline & Higher than Bachelor's degree & 20 & $(9.52 \%)$ & 33 & $(15.71 \%)$ & 53 & $(12.62 \%)$ \\
\hline \multirow{8}{*}{ Occupation } & Government service & 28 & $(13.33 \%)$ & 50 & $(23.81 \%)$ & 78 & $(18.57 \%)$ \\
\hline & Private service & 64 & $(30.48 \%)$ & 63 & $(30.00 \%)$ & 127 & $(30.24 \%)$ \\
\hline & Business & 96 & $(45.71 \%)$ & 49 & $(23.33 \%)$ & 145 & $(34.52 \%)$ \\
\hline & Student & 8 & $(3.81 \%)$ & 32 & $(15.24 \%)$ & 40 & $(9.52 \%)$ \\
\hline & Housewife & 1 & $(0.48 \%)$ & 5 & $(2.38 \%)$ & 6 & $(1.43 \%)$ \\
\hline & Unemployed & 2 & $(0.95 \%)$ & 1 & $(0.48 \%)$ & 3 & $(0.71 \%)$ \\
\hline & Retired & 5 & $(2.38 \%)$ & 7 & $(3.33 \%)$ & 12 & $(2.86 \%)$ \\
\hline & Others & 6 & $(2.86 \%)$ & 3 & $(1.43 \%)$ & 9 & $(2.14 \%)$ \\
\hline \multirow{6}{*}{$\begin{array}{c}\text { Income } \\
\text { (THB/Month) }\end{array}$} & Lower than 15,000 & 28 & $(13.33 \%)$ & 48 & $(22.86 \%)$ & 76 & $(18.10 \%)$ \\
\hline & $15,001-25,000$ & 89 & $(42.38 \%)$ & 88 & $(41.90 \%)$ & 177 & $(42.14 \%)$ \\
\hline & $25,001-35,000$ & 55 & $(26.19 \%)$ & 39 & $(18.57 \%)$ & 94 & $(22.38 \%)$ \\
\hline & $35,001-50,000$ & 21 & $(10.00 \%)$ & 17 & $(8.10 \%)$ & 38 & $(9.05 \%)$ \\
\hline & $50,001-100,000$ & 11 & $(5.24 \%)$ & 13 & $(6.19 \%)$ & 24 & $(5.71 \%)$ \\
\hline & More than 100,000 & 6 & $(2.86 \%)$ & 5 & $(2.38 \%)$ & 11 & $(2.62 \%)$ \\
\hline
\end{tabular}


Table 3. Cont.

\begin{tabular}{|c|c|c|c|c|c|c|c|}
\hline \multirow{2}{*}{\multicolumn{2}{|c|}{ Characteristics }} & \multicolumn{6}{|c|}{ Quantity (Percentage) } \\
\hline & & \multicolumn{2}{|c|}{ Car } & \multicolumn{2}{|c|}{ Air } & \multicolumn{2}{|c|}{ Total } \\
\hline \multirow{5}{*}{ Trip Purpose } & Education & 0 & $(0.00 \%)$ & 13 & $(6.19 \%)$ & 13 & $(3.10 \%)$ \\
\hline & Work/Business & 71 & $(33.81 \%)$ & 68 & $(32.38 \%)$ & 139 & $(33.10 \%)$ \\
\hline & Tourism & 67 & $(31.90 \%)$ & 82 & $(39.05 \%)$ & 149 & $(35.48 \%)$ \\
\hline & Social & 66 & $(31.43 \%)$ & 43 & $(20.48 \%)$ & 109 & $(25.95 \%)$ \\
\hline & Others & 6 & $(2.86 \%)$ & 4 & $(1.90 \%)$ & 10 & $(2.38 \%)$ \\
\hline \multirow{2}{*}{$\begin{array}{c}\text { Bearer of Travel } \\
\text { Expenses }\end{array}$} & Self/Family & 187 & $(89.05 \%)$ & 178 & $(84.76 \%)$ & 365 & $(86.90 \%)$ \\
\hline & Employer & 23 & $(10.95 \%)$ & 32 & $(15.24 \%)$ & 55 & $(13.10 \%)$ \\
\hline \multirow{4}{*}{$\begin{array}{l}\text { Travel Group } \\
\text { Size }\end{array}$} & Alone & 39 & $(18.57 \%)$ & 97 & $(46.19 \%)$ & 136 & $(32.38 \%)$ \\
\hline & 2 persons & 87 & $(41.43 \%)$ & 65 & $(30.95 \%)$ & 152 & $(36.19 \%)$ \\
\hline & 3 persons & 31 & $(14.76 \%)$ & 24 & $(11.43 \%)$ & 55 & $(13.10 \%)$ \\
\hline & More than 3 persons & 53 & $(25.24 \%)$ & 24 & $(11.43 \%)$ & 77 & $(18.33 \%)$ \\
\hline \multirow{4}{*}{$\begin{array}{l}\text { Duration of Stay } \\
\text { at Destination }\end{array}$} & 1 to 3 days & 125 & $(59.52 \%)$ & 131 & $(62.38 \%)$ & 256 & $(60.95 \%)$ \\
\hline & 4 to 7 days & 69 & $(32.86 \%)$ & 75 & $(35.71 \%)$ & 144 & $(34.29 \%)$ \\
\hline & 8 to 30 days & 15 & $(7.14 \%)$ & 4 & $(1.90 \%)$ & 19 & $(4.52 \%)$ \\
\hline & More than 30 days & 1 & $(0.48 \%)$ & 0 & $(0.00 \%)$ & 1 & $(0.24 \%)$ \\
\hline \multirow{5}{*}{$\begin{array}{l}\text { Trips in Last } 6 \\
\text { Months }\end{array}$} & 1 trip & 124 & $(59.05 \%)$ & 121 & $(57.62 \%)$ & 245 & $(58.33 \%)$ \\
\hline & 2 to 3 trips & 57 & $(27.14 \%)$ & 70 & $(33.33 \%)$ & 127 & $(30.24 \%)$ \\
\hline & 4 to 5 trips & 18 & $(8.57 \%)$ & 13 & $(6.19 \%)$ & 31 & $(7.38 \%)$ \\
\hline & 6 to 8 trips & 6 & $(2.86 \%)$ & 4 & $(1.90 \%)$ & 10 & $(2.38 \%)$ \\
\hline & More than 8 trips & 5 & $(2.38 \%)$ & 2 & $(0.95 \%)$ & 7 & $(1.67 \%)$ \\
\hline
\end{tabular}

\subsubsection{Ridership Projection}

From Table 1, it is observed that the number of trips per year for car, bus, train, and air travelers for the period from $2017-2018$ changed by $+4.19 \%,-7.57 \%,-18.34 \%$ and $+5.96 \%$, respectively. As per the study conducted by TransPod in Thailand, the construction of a hyperloop between Bangkok and Chiang Mai will take about 5 years [14]. In view of this, the travel volume and ridership (modal share) is also projected for the year 2025. The modal split for the year 2020 and 2025, based on the growth rate for the year 2017-2018, is presented in Table 4.

Table 4. Projected number of trips in Bangkok-Chiang Mai Sector for 2020 and 2025.

\begin{tabular}{ccccc}
\hline \multirow{2}{*}{ Mode } & \multicolumn{2}{c}{$\mathbf{2 0 2 0}$} & \multicolumn{2}{c}{$\mathbf{2 0 2 5}$} \\
\cline { 2 - 5 } & Trips & Trips & \% \\
\hline Car & $7,156,617$ & 45.80 & $8,784,850$ & 45.70 \\
Bus & 969,148 & 6.20 & 653,784 & 3.40 \\
Train & 236,865 & 1.52 & 85,986 & 0.45 \\
Air & $7,260,902$ & 46.50 & $9,697,821$ & 50.45 \\
\hline Total & $15,623,532$ & 100.00 & $19,222,441$ & 100.00 \\
\hline
\end{tabular}

It may be noted that the percentage share of car and air combined for the year 2020 works out to $91.27 \%$, whereas for bus and rail combined it works out to only $8.73 \%$. For the year 2025, the percentage share of car and air combined for the year 2025 works out to $96.15 \%$, whereas for bus and rail combined, it works out to only $3.85 \%$.

\section{Results and Discussion}

\subsection{Ranking of Factors Influencing Intercity Travel}

Respondents were asked about their preferences in terms of low travel cost, less travel time, high frequency, safety, comfort and low carbon emissions for long distance travel and rank them from 1 to 6 ( 1 being most preferred and 6 being least preferred). 
Respondents traveling by car ranked comfort as the most important factor, followed by low travel cost, high frequency, safety and less travel time. Low carbon emission was considered the least important (Figure 1).

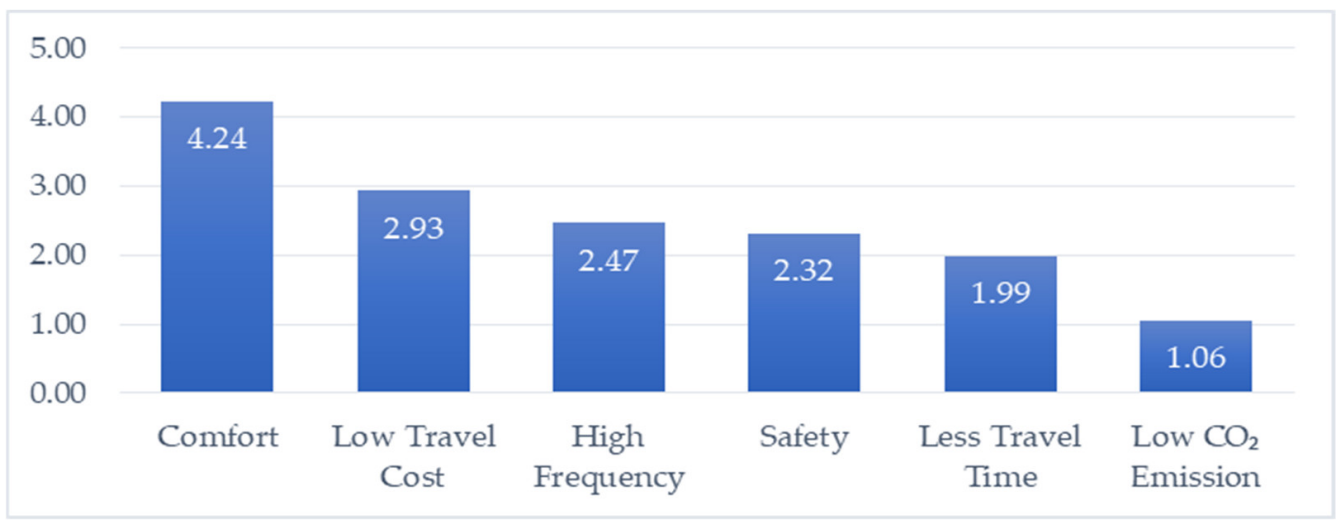

Figure 1. Ranking of factors influencing intercity travel by car respondents.

Respondents traveling by air ranked less travel time as the most important factor, closely followed by low travel cost and subsequently followed by high frequency, comfort, safety and low carbon emission (Figure 2).

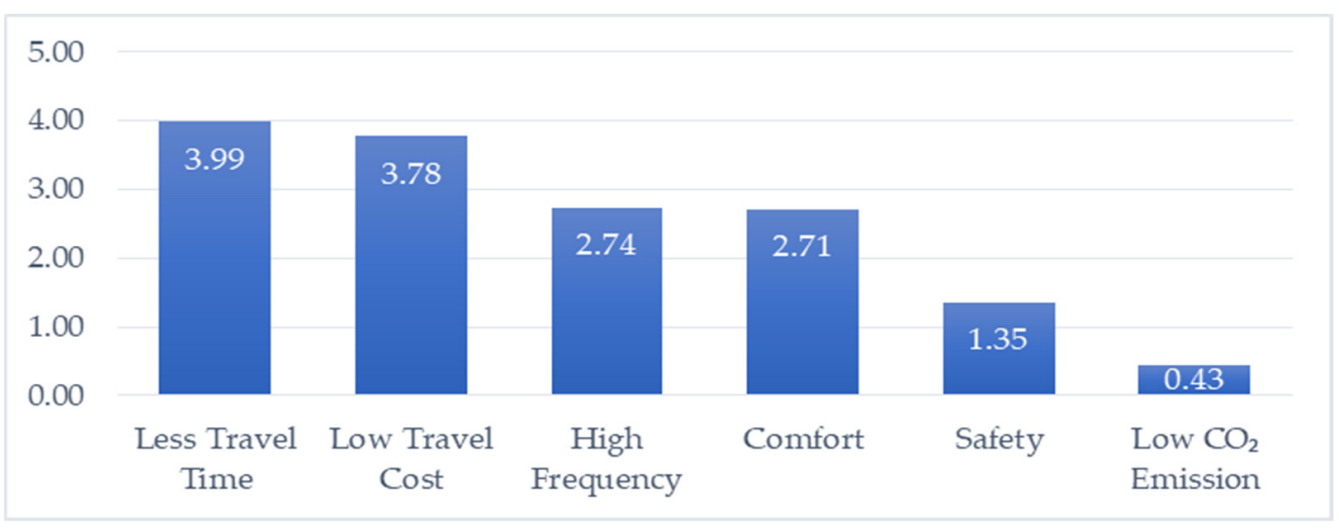

Figure 2. Ranking of factors influencing intercity travel by air respondents.

Considering all the respondents, comfort was ranked as the most important factor closely followed by low travel cost. Low carbon emission was considered the least important factor (Figure 3).

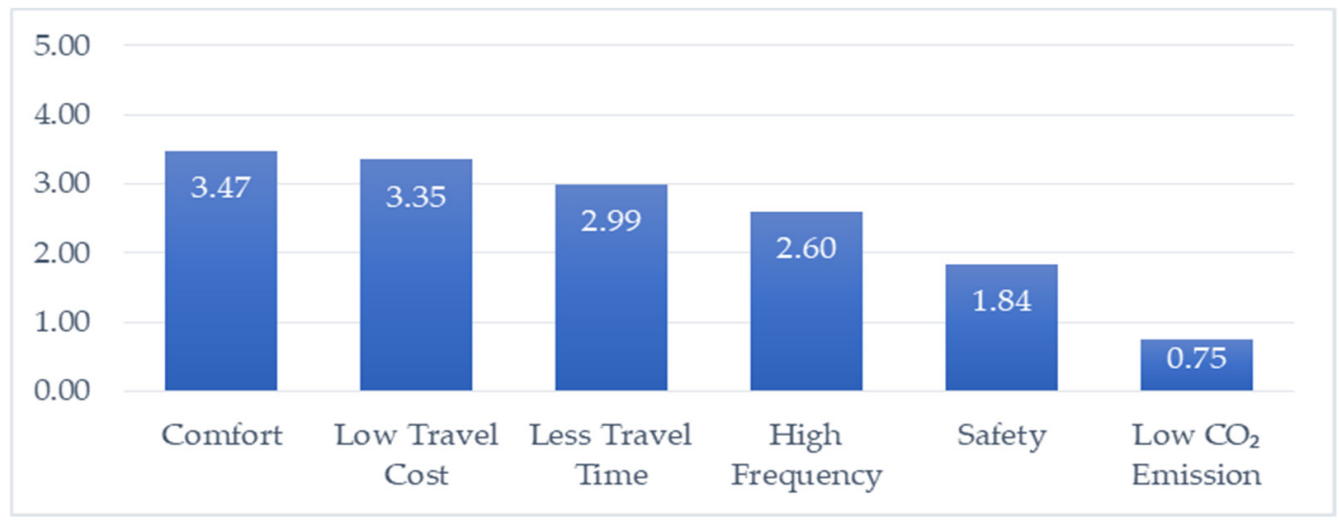

Figure 3. Ranking of factors influencing intercity travel by both car and air respondents. 


\subsection{The Model}

Several multinomial logit models are developed from the survey data and the best fit model is used to further develop a nested logit model. The discrete choice models are developed using NLOGIT statistical analysis software. Air travel is considered the base alternative for model development and thus, alternative specific constant for air is normalized to zero.

Various socioeconomic and trip characteristic variables are included for the model development. Some are added as continuous variables while others are added categorically. The gender (GEN) was categorized as 1 for male and 0 for female. Education level (EDU) is coded from 1 to 5 ( 1 = lower than high school, $2=$ high school or equivalent, $3=$ diploma, $4=$ Bachelor's degree and $5=$ higher than Bachelor's degree). Age (AGE) is entered as specified by the respondent. Monthly income (INC) in THB was coded as 7500 (for income level <15,000), 20,000 (for income level 15,001-25,000), 30,000 (for income level 25,001-35,000), 42,500 (for income level 35,001-50,000), 75,000 (for income level $50,001-100,000$ ) and 150,000 (for income level > 100,000). The bearer of trip expenses (EXP) variable was set equal to 1 if the expenses were borne by the traveler or the traveler's family and 2 if the expenses were borne by the employer. The duration of stay at the destination (DOS) variable was measured from 1 to $4(1=1-3$ days, $2=4-7$ days, $3=8-30$ days, and $4=$ more than 30 days). The travel group size (GRP) and number of trips in the last 6 months (TRP) variables are entered as specified by the respondent.

The Hausman test of the IIA assumption is performed on the best fit MNL model before proceeding to the NL model development. As the $p$-value obtained from the test is less than the critical $p$-value of 0.05 , the null hypothesis of the IIA assumption is rejected at a $95 \%$ confidence level and thus a more complex NL model is developed. The tree structure used for the NL model development is shown in Figure 4. For the NL model development, IV parameter for the private branch is normalized to 1.0. To avoid the problem of identification, the scale parameters at level 1 are also normalized to 1.0 (i.e., random utility model specification 1, RU1). The start values for the maximum likelihood procedure are obtained from a non-nested NL model. In addition, the utility functions are only specified at level 1.

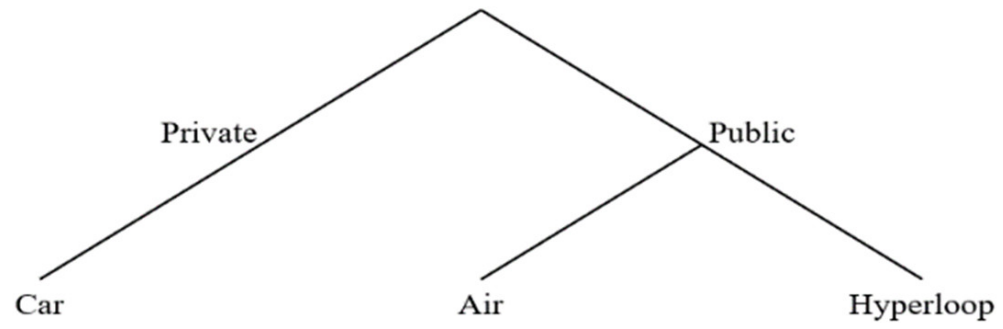

Branch (Level 2)

Figure 4. Tree Structure for NL Model Development.

As SP models do not produce the initial market shares as observed in the real world, the alternative-specific constants obtained from the model are therefore calibrated using true market shares, as obtained for the year 2018. As hyperloop is not available in the current market, a choice-based weight of 1.0 is used for its calibration [35]. The values of the parameters estimated from the calibrated NL model are shown in Table 5.

All parameter estimates have a logical sign and are significant at $95 \%$ confidence level, apart from the alternative-specific constant for hyperloop, thus suggesting that an equal proportion of travelers selecting air and hyperloop provided the effect of the other variables is zero.

The parameter estimates for the level-of-service variables, i.e., total travel time and total travel cost, are negative. This implies that with an increase in the total travel time and total travel cost, the utility of all three modes would decrease. It was observed that the disutility would be at the maximum in the case of hyperloop, followed by air and 
car. Numerous studies have indicated that travelers tend to choose cheaper modes of transport $[43,44]$. In addition, studies have shown that these variables have the highest impact on a traveler's mode choice behavior [45-48].

Table 5. Parameter estimates for the calibrated NL model specification.

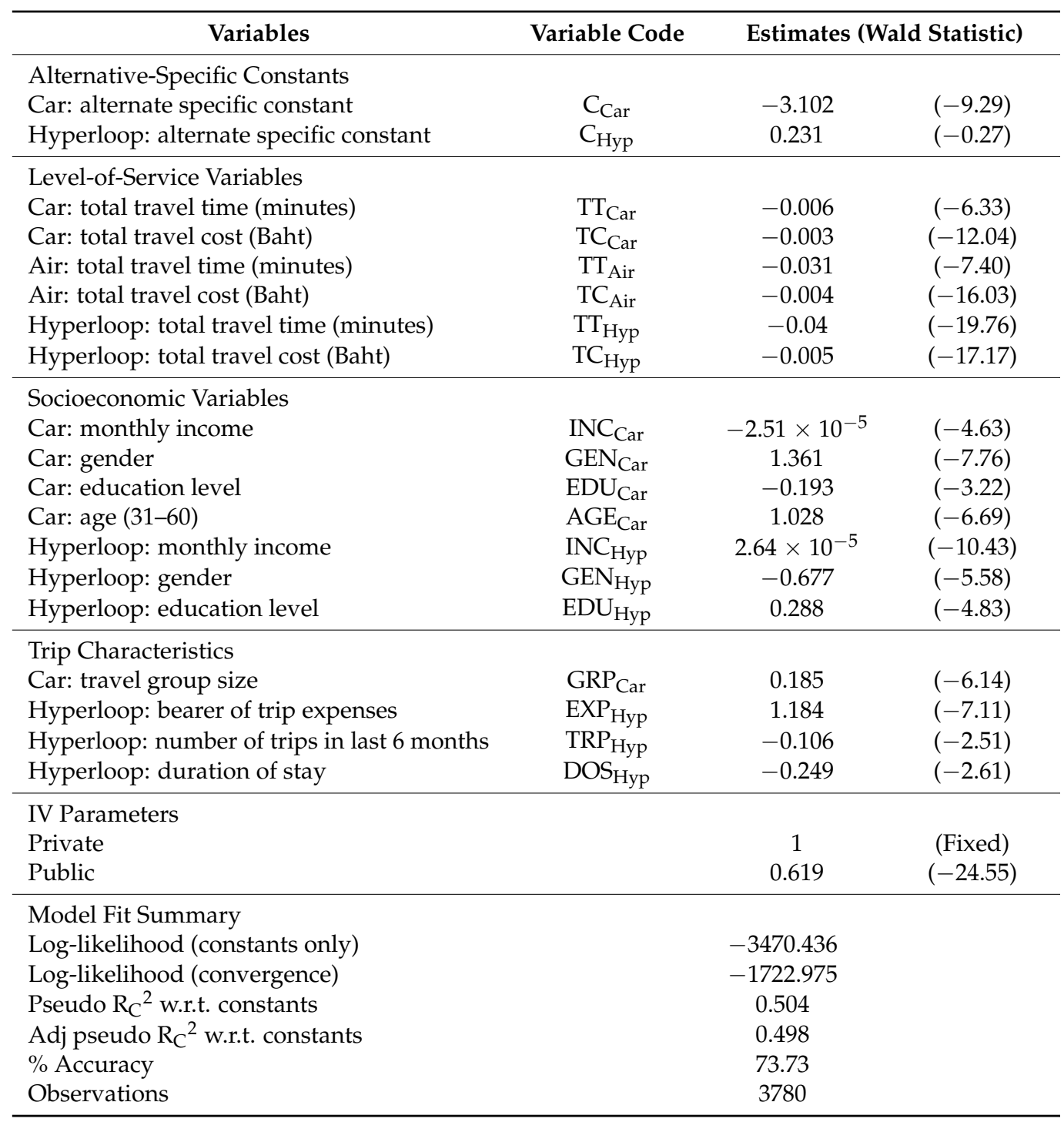

Among socioeconomic variables, the variables that significantly contributed to the mode choice are monthly income, gender, education level and age. The parameter estimates for the monthly income of the car is negative; thus, with an increase in income there is a decrease in tendencies to choose the car. In the case of the hyperloop, the income parameter is positive, indicating a shift towards hyperloop with an increase in income. A study conducted in Libya reported that individuals with higher income are more likely to choose air over other modes for intercity travel in Libya [23]. The parameter estimate for the gender of the car traveler is positive, while it is negative for hyperloop. Therefore, males tend to choose the car more to travel instead of air and hyperloop, while females tend to prefer air and hyperloop instead of private cars, perhaps because of safety and comfort reasons. A similar trend was observed in Indonesia [49,50]. The parameter estimates for education is negative for the car, while it is positive for the hyperloop, suggesting that less educated travelers are more likely to use the car while more educated travelers are likely to use hyperloop when compared with air for intercity travel. A study in Thailand found that travelers with higher levels of education are more likely to travel by air when compared to 
cars for intercity travel between Bangkok and Chiang Mai [51]. As the parameter estimate for the age with the car is positive, the utility for the car increases for the age group 31 to 60 years as compared to air. People who are less than 31 years or more than 60 years prefer to travel by air.

Trip characteristics, such as travel group size, bearer of trip expenses, number of trips in last 6 months and duration of stay at the destination also significantly impact the intercity mode choice. The parameter estimate for the travel group size for the car is positive. Thus, if the number of co-travelers increases, there is an increase for the utility for the car. In addition, a study conducted in the southern corridor of Thailand found that the utility of the car increases with an increase in the number of co-travelers [22]. A clear shift to hyperloop from air is observed in those cases, where the travel expenses are borne by the employer, as the parameter estimate for the bearer of travel expenses in the case of hyperloop is positive. Another study reported that individuals for whom the company or employer issues the fares are more likely choose to travel by air when compared to the car for the intercity mode choice between Bangkok and Chiang Mai [51]. The parameter estimates for the number of trips in the last 6 months for hyperloop is negative. The reason for this could be that the people who travel more in the corridor are less likely to use hyperloop, possibly due to the inertia effect [52]. Travelers who are likely to stay longer at the destination do not prefer hyperloop, as suggested by the negative sign of the duration of stay at the destination parameter for hyperloop. This could possibly be because travelers prefer to use cars when they plan to stay longer at the destination [23].

The utility functions at level 1 from the parameter estimates obtained from the calibrated NL model are given by the following equations:

$$
\begin{gathered}
\mathrm{U}_{\text {Car }}=(-3.102)+\left(-0.006 \times \mathrm{TT}_{\text {Car }}\right)+\left(-0.003 \times \mathrm{TC}_{\text {Car }}\right)+\left(-0.0000251 \times \mathrm{INC}_{\text {Car }}\right) \\
+\left(1.361 \times \mathrm{GEN}_{\text {Car }}\right)+\left(-0.193 \times \mathrm{EDU}_{\mathrm{Car}}\right)+\left(1.028 \times \mathrm{AGE}_{\mathrm{Car}}\right)+\left(0.185 \times \mathrm{GRP}_{\mathrm{Car}}\right) \\
\mathrm{U}_{\text {Air }}=\left(-0.031 \times \mathrm{TT}_{\text {Air }}\right)+\left(-0.004 \times \mathrm{TC}_{\text {Air }}\right) \\
\mathrm{U}_{\text {Hyperloop }}=(0.231)+\left(-0.040 \times \mathrm{TT}_{\text {Hyp }}\right)+\left(-0.005 \times \mathrm{TC}_{\text {Hyp }}\right)+ \\
\left(0.0000264 \times \mathrm{INC}_{\text {Hyp }}\right)+\left(-0.677 \times \mathrm{GEN}_{\text {Hyp }}\right)+\left(-0.288 \times \mathrm{EDU}_{\text {Hyp }}\right)+ \\
\left(1.184 \times \mathrm{EXP}_{\text {Hyp }}\right)+\left(-0.106 \times \mathrm{TRP}_{\text {Hyp }}\right)+\left(-0.249 \times \mathrm{DOS}_{\text {Hyp }}\right)
\end{gathered}
$$

The utility functions at level 2 as obtained from the calibrated NL model are given by the following equations:

$$
\begin{gathered}
\mathrm{U}_{\text {Private }}=\mathrm{U}_{\text {Car }} \\
\mathrm{U}_{\text {Public }}=\left(0.619 \times \ln \left(\exp ^{\mathrm{U}_{\text {Air }}}+\exp ^{\mathrm{U}_{\text {Hyperloop }}}\right)\right)
\end{gathered}
$$

\subsection{Applications}

\subsubsection{Elasticity Analysis}

Elasticity analysis is usually performed for the purpose of prediction. When the hyperloop system is implemented, the attributes might be different than those utilized for the analysis, such as higher travel time and/or travel cost. Both direct and cross elasticities are measured for hyperloop to inspect changes in total travel cost, total travel time and monthly income. The aggregation method employed is the probability weighted sample enumeration (PWSE). The values are presented in Table 6.

Table 6. Elasticity of demand for hyperloop.

\begin{tabular}{cccc}
\hline Elasticity & Total Travel Cost & Total Travel Time & Income (THB/Month) \\
\hline Car & 1.398 & 1.07 & -0.105 \\
Air & 1.89 & 1.431 & -0.175 \\
Hyperloop & -1.482 & -1.126 & 0.129 \\
\hline
\end{tabular}

From Table 6, it is inferred that if total travel cost for hyperloop increases by $1 \%$, 
the demand for hyperloop will decrease by $1.482 \%$ and the corresponding demand for car and air will increase by $1.398 \%$ and $1.890 \%$, respectively. The highest value elasticity of hyperloop is obtained for total travel cost, followed by total travel time and monthly income. As the rise in income level is certain, and assuming total travel cost and total travel time do not vary at the implementation stage, the demand of hyperloop is likely to increase. In conclusion, to maintain the market share for hyperloop, priority must be given to cost reduction. Similar findings were reported for a HSR study conducted in Sweden [53].

\subsubsection{Value of Travel Time Savings}

The value of travel time savings (VTTS) indicates the trade-off a person is likely to make between travel cost and travel time. For analysis, various trip purposes were clubbed in two categories viz. mandatory (comprising of business and education purpose only) and others. The VTTS values obtained were alternative-specific and are shown in Table 7.

Table 7. Value of travel time savings for different trip purposes.

\begin{tabular}{cccc}
\hline \multirow{2}{*}{ Trip Purpose } & \multicolumn{3}{c}{ Modes (Baht/Hour) } \\
\cline { 2 - 4 } & Car & Air & Hyperloop \\
\hline Mandatory & 124.015 & 413.825 & 515.542 \\
Other & 85.039 & 283.766 & 353.514 \\
\hline
\end{tabular}

It is observed that VTTS values are higher when the trip purpose is mandatory and this result is consistent with findings from previous HSR studies conducted in Japan, Spain and Sweden [54-56]. The individuals who prefer to travel by hyperloop are willing to spend the most to save unit time, followed by air and car. Similar findings were reported from HSR studies conducted in Spain and Italy, where the VTTS values for the car were considerably lower than that of the air and HSR modes [16,57].

\subsubsection{Obtaining Ridership Estimates with Hyperloop}

The choice probabilities for the car, air and hyperloop obtained from the calibrated NL model are $17.66 \%, 28.86 \%$ and $53.48 \%$, respectively. The choice probabilities obtained from the model are used to estimate the projected ridership for the current year (i.e., 2020) and for the year 2025, with hyperloop keeping the growth/de-growth rate for all existing modes at the level of 2017-2018. For the estimation of ridership by hyperloop, only air and car passengers are considered. As the passengers travelling by rail and bus are not considered, the percentage share of passengers travelling by rail and bus was calculated based on the growth rate for the period 2017-2018. Assuming that no high-speed rail project comes up for this sector, the projected ridership for the year 2020 and 2025 with hyperloop are shown in Table 8 . It is estimated that approximately 9.88 million trips (51.42\%) will shift towards hyperloop in the year 2025 .

Table 8. Projected number of trips in Bangkok-Chiang Mai Sector for 2020 and 2025 with hyperloop.

\begin{tabular}{ccccc}
\hline \multirow{2}{*}{ Mode } & \multicolumn{2}{c}{$\mathbf{2 0 2 0}$} & \multicolumn{2}{c}{$\mathbf{2 0 2 5}$} \\
\cline { 2 - 5 } & Trips & \% & Trips & \% \\
\hline Car & $2,546,033$ & 16.30 & $3,263,910$ & 16.98 \\
Bus & 969,148 & 6.20 & 653,784 & 3.40 \\
Train & 236,865 & 1.52 & 85,986 & 0.45 \\
Air & $4,161,281$ & 26.63 & $5,334,592$ & 27.75 \\
Hyperloop & $7,710,205$ & 49.35 & $9,884,169$ & 51.42 \\
\hline Total & $15,623,532$ & 100.00 & $19,222,441$ & 100.00 \\
\hline
\end{tabular}




\section{Conclusions}

In order to assess the viability of any new technology or transportation mode, the assessment of the willingness of mode shift is very important. The study used a nested logit model to estimate the potential shift of car and air travelers to hyperloop by analyzing the SP data associated with the Bangkok-Chiang Mai corridor. Based on the calibrated NL model, the variable contributing the most to the model is the total travel cost followed by total travel time. With an increase in total travel time and total travel cost, the maximum disutility is observed in hyperloop, followed by air and car.

In terms of socioeconomic characteristics, it is observed that with an increase in monthly income there is an increase in the tendency to choose hyperloop, as compared to car and air. As far as gender is concerned, males tend to choose the car more to travel instead of public modes, while females tend to prefer public modes instead of private cars. Less educated travelers are more likely to use the car while more educated travelers are likely to use hyperloop, compared to air. In terms of age, people in the age group 31 to 60 years are more likely to use the car in comparison to hyperloop and air.

As far as trip characteristics were concerned, the utility of the car increases with the increase in the number of co-travelers, compared to air and hyperloop. A clear shift to hyperloop from air is observed in those cases where the travel expenses are borne by the employer. People who travel more frequently in the corridor are less likely to use hyperloop.

From the model, it is inferred that people who prefer to travel by hyperloop are likely to spend the most to save a unit time. The value of travel time savings (in THB per hour) for the hyperloop, air and car were 515.54, 413.82 and 124.01, respectively.

It is projected that a total of $15,623,532$ and $19,222,441$ trips will be made in the years 2020 and 2025, respectively, between Bangkok and Chiang Mai. The choice probabilities obtained from the model for the car, air and hyperloop are $17.65 \%, 28.86 \%$ and $53.47 \%$, respectively. Further, the number of trips per year for hyperloop in 2020 and 2025 are projected to be 7,710,205 (49.34\%) and 9,884,169 (51.42\%), respectively.

Survey results also revealed that the preferences of the passengers in order of priorities for long distance travel are comfort, low travel cost, less travel time, safety, high frequency of travel mode and low $\mathrm{CO}_{2}$ emission.

The authors also note that this analysis is based on a few limitations, which should be improved through future research, such as the inclusion of respondents travelling by bus and rail in the survey. Further, attributes such as ease of access, safety, access to station/airport, etc., may also be incorporated in the analysis. Hyperloop, being a new concept, has not yet reached the masses, in terms of their awareness of it. During the field surveys, many efforts were made to explain to the respondents about the hyperloop; however, it is felt that the more prior awareness about the new mode there is, the better would be the results. It is therefore suggested that appropriate use of mass communication modes should be done to generate awareness before conducting surveys for new technologies. This will also help with reduction time for the administration of the survey questionnaire, thereby increasing the chances of more comprehensive responses from the respondents. Further, it would be worthwhile to validate the findings by reconducting the survey over different time periods.

Author Contributions: Conceptualization, P.A. and S.P.; methodology, P.A. and S.P.; software and formal analysis, P.A.; writing-review and editing, P.A.; supervision, S.P. All authors have read and agreed to the published version of the manuscript.

Funding: This research received no external funding.

Institutional Review Board Statement: The study was conducted according to the guidelines of the Declaration of Helsinki, and approved by the Institutional Review Board.

Informed Consent Statement: Informed consent was obtained from all subjects involved in the study. 
Data Availability Statement: The data presented in this study are available on request from the corresponding author.

Acknowledgments: The authors would like to extend their sincere thanks to officers of Ayutthaya Highway Police, Don Mueang International Airport and Chiang Mai International Airport for their support during data collection.

Conflicts of Interest: The authors declare no conflict of interest.

\section{References}

1. TomTom. Traffic Index Ranking. 2019. Available online: https://www.tomtom.com/en_gb/traffic-index/ranking/ (accessed on 28 March 2020).

2. Chong, D. The impact of traffic congestions on tourist behavior: Case study of Chiang Mai, Thailand. In Proceedings of the 14th ApacChrie Conference, Bangkok, Thailand, 11-13 May 2016.

3. National Statistical Office. 2010 Population and Housing Census. 2012. Available online: http://popcensus.nso.go.th/en/report. php (accessed on 27 September 2019).

4. Pita, P.; Chunark, P.; Limmeechokchai, B. $\mathrm{CO}_{2}$ Reduction Perspective in Thailand's Transport sector towards 2030. Energy Procedia 2017, 138, 635-640. [CrossRef]

5. Janssens-Maenhout, G.; Crippa, M.; Guizzardi, D.; Muntean, M.; Schaaf, E.; Olivier, J.G.J.; Peters, J.A.H.W.; Schure, K.M. Fossil $\mathrm{CO}_{2}$ \& GHG Emissions of All World Countries; Publications Office of the European Union: Luxembourg, $2017 ;$ Volume 107877.

6. IRENA RES. International Renewable Energy Agency; Renewable Energy Target Setting: Abu Dhabi, United Arab Emirates, 2015.

7. SpaceX. Hyperloop Alpha; SpaceX: Hawthorne, CA, USA, 2013.

8. Taylor, C.L.; Hyde, D.J.; Barr, L.C. Hyperloop Commercial Feasibility Analysis; John, A., Ed.; Volpe National Transportation System Center: Cambridge, MA, USA, 2016.

9. Decker, K.; Chin, J.; Peng, A.; Summers, C.; Nguyen, G.; Oberlander, A.; Sakib, G.; Sharifrazi, N.; Heath, C.; Gray, J.; et al. Conceptual Feasibility Study of the Hyperloop Vehicle for Next-Generation Transport; American Institute of Aeronautics and Astronautics: Reston, VA, USA, 2017.

10. Walker, R. Hyperloop: Cutting through the Hype; Transport Research Laboratory: London, UK, 2018.

11. Gkoumas, K.; Christou, M. A Triple-Helix Approach for the Assessment of Hyperloop Potential in Europe. Sustainability 2020, 12, 7868. [CrossRef]

12. Van Goeverden, C.; Milakis, D.; Janic, M.; Konings, J.W. Performances of the HL (Hyperloop) Transport System. In Proceedings of the BIVEC-GIBET Transport Research Days, Liège, Belgium, 18-19 May 2017; pp. 29-43.

13. Bangkok Post. Losses Predicted for High-Speed Railway. 25 July 2018. Available online: https://www.bangkokpost.com/ thailand/general/1509418/losses-predicted-for-high-speed-railway (accessed on 28 March 2020).

14. TransPod. Hyperloop in Thailand-Preliminary study on the implementation of a TransPod Hyperloop line in Thailand; TransPod: Toronto, ON, Canada, 2019.

15. Lubis, H.A.; Pantas, V.B.; Farda, M. Demand Forecast of Jakarta-Surabaya High Speed Rail based on Stated Preference Method. Int. J. Technol. 2019, 10, 405-416. [CrossRef]

16. Román, C.; Espino, R.; Martín, J.C. Analyzing Competition between the High Speed Train and Alternative Modes. The Case of the Madrid-Zaragoza-Barcelona Corridor. J. Choice Model. 2010, 3, 84-108. [CrossRef]

17. Sperry, B.R.; Burris, M.; Woosnam, K.M. Investigating the impact of high-speed rail equipment visualization on mode choice models: Case study in central Texas. Case Stud. Transp. Policy 2017, 5, 560-572. [CrossRef]

18. Burge, P.; Kim, C.W.; Rohr, C. Modelling Demand for Long-Distance Travel in Great Britain: Stated Preference Surveys to Support the Modelling of Demand for High-Speed Rail; RAND Corporation: Santa Monica, CA, USA, 2011.

19. Chen, C.; Gong, H.; Paaswell, R. Role of the built environment on mode choice decisions: Additional evidence on the impact of density. Transportation 2008, 35, 285-299. [CrossRef]

20. Tyrinopoulos, Y.; Antoniou, C. Factors affecting modal choice in urban mobility. Eur. Transp. Res. Rev. 2013, 5, 27-39. [CrossRef]

21. Wójcik, S. The determinants of travel mode choice: The case of Łódź, Poland. Bulletin of Geography. Socio-Econ. Ser. 2019, 44, 93-101.

22. Chantruthai, P.; Taneerananon, S.; Taneerananon, P. A Study of Competitiveness between Low Cost Airlines and High-Speed-Rail: A Case Study of Southern Corridor in Thailand. Eng. J. 2014, 18, 141-162. [CrossRef]

23. Miskeen, M.A.A.B.; Alhodairi, A.M.; Rahmat, R.A.O.K. Modeling a Multinomial Logit Model of Intercity Travel Mode Choice Behavior for All Trips in Libya. Int. J. Civ. Environ. Eng. 2013, 7, 636-645.

24. Al-Ahmadi, H.M. The Effects of Mode Perceptions on Intercity Mode-Choice Behavior in Saudi Arabia. Eur. J. Bus. Manag. 2017, 9, 62-71.

25. Minal, S.; Chalumuri, R.S. Mode Choice Analysis: The Data, the Models and Future Ahead. Int. J. Traffic Transp. Eng. 2014, 4, 269-285.

26. McFadden, D. Conditional Logit Analysis of Qualitative Choice Behavior; University of California at Berkeley: Berkeley, CA, USA, 1973.

27. Domencich, T.A.; McFadden, D. Urban Travel Demand-A Behavioral Analysis; North-Holland Publishing Co.: Amsterdam, The Netherlands, 1975. 
28. Maddala, G.S. Limited-Dependent and Qualitative Variables in Econometrics; Cambridge University Press: Cambridge, UK, 1986.

29. Ben-Akiva, M.E.; Lerman, S.R. Discrete Choice Analysis: Theory and Application to Travel Demand; MIT Press: Cambridge, MA, USA, 1985; Volume 9.

30. Park, Y.; Ha, H.-K. Analysis of the impact of high-speed railroad service on air transport demand. Transp. Res. Part E Logist. Transp. Rev. 2006, 42, 95-104. [CrossRef]

31. Vickerman, R. High-speed rail in Europe: Experience and issues for future development. Ann. Reg. Sci. 1997, 31, 21-38. [CrossRef]

32. Hensher, D.A. A practical approach to identifying the market potential for high speed rail: A case study in the Sydney-Canberra corridor. Transp. Res. Part A Policy Pract. 1997, 31, 431-446. [CrossRef]

33. Cheng, Y.-H. High-speed rail in Taiwan: New experience and issues for future development. Transp. Policy 2010, 17, 51-63. [CrossRef]

34. Bhat, C.R. Accommodating variations in responsiveness to level-of-service measures in travel mode choice modeling. Transp. Res. Part A Policy Pract. 1998, 32, 495-507. [CrossRef]

35. Hensher, D.A.; Rose, J.M.; Greene, W.H. Applied Choice Analysis: A Primer; Cambridge University Press: Cambridge, UK, 2005.

36. Gebeyehu, M.; Takano, S.-E. Modeling the Relationship between Traveler Level of Satisfaction and Their Mode Choice Behavior using Ordinal Models. J. Transp. Res. Forum 2011, 47. [CrossRef]

37. Koppelman, F.S.; Bhat, C. A Self Instructing Course in Mode Choice Modeling: Multinomial and Nested Logit Models; U.S. Department of Transportation: Washington, DC, USA, 2006.

38. Train, K.E. Discrete Choice Methods with Simulation; Cambridge University Press: Cambridge, UK, 2003.

39. Wang, Y.; Li, L.; Wang, L.; Moore, A.; Staley, S.; Li, Z. Modeling traveler mode choice behavior of a new high-speed rail corridor in China. Transp. Plan. Technol. 2014, 37, 466-483. [CrossRef]

40. Sanko, N. Guidelines for Stated Preference Experiment Design. Master's Thesis, Ecole Nationale des Ponts et Chaussées, Paris, France, 2001.

41. Energy Policy and Planning Office-Ministry of Energy. Retail Price of Oil. 2019. Available online: http://www.eppo.go.th/ epposite/index.php/th/petroleum/price/oil-price?issearch=1\&isc=1\&ordering=publishUp\&category_id=558\&xf_6=18 (accessed on 4 January 2020).

42. International Energy Agency. International Comparison of Light-Duty Vehicle Fuel Economy 2005-2015; International Energy Agency: Paris, France, 2017.

43. Ashiabor, S.; Baik, H.; Trani, A. Logit Models for Forecasting Nationwide Intercity Travel Demand in the United States. Transp. Res. Rec. J. Transp. Res. Board 2007, 2007, 1-12. [CrossRef]

44. Kumar, C.V.; Basu, D.; Maitra, B. Modeling Generalized Cost of Travel for Rural Bus Users: A Case Study. J. Public Transp. 2004, 7, 4. [CrossRef]

45. Zhang, X.; Guan, H.; Zhu, H.; Zhu, J. Analysis of Travel Mode Choice Behavior Considering the Indifference Threshold. Sustainability 2019, 11, 5495. [CrossRef]

46. Witchayaphong, P.; Pravinvongvuth, S.; Kanitpong, K.; Sano, K.; Horpibulsuk, S. Influential Factors Affecting Travelers' Mode Choice Behavior on Mass Transit in Bangkok, Thailand. Sustainability 2020, 12, 9522. [CrossRef]

47. Madhuwanthi, R.A.M.; Marasinghe, A.; Rpc, J.; Dharmawansa, A.D.; Nomura, S. Factors Influencing to Travel Behavior on Transport Mode Choice-A Case of Colombo Metropolitan Area in Sri Lanka. Int. J. Affect. Eng. 2015, 15, 63-72. [CrossRef]

48. Dewi, A.U.; Munawar, M. Research on Factors Affecting Travel Behavior on Choice of Transportation Means for Working Activity: Case Study Yogyakarta City, Indonesia; Semantic Scholar Publishing: Seattle, WA, USA, 2010.

49. Yagi, S.; Mohammadian, A. Joint Models of Home-Based Tour Mode and Destination Choices. Transp. Res. Rec. J. Transp. Res. Board 2008, 2076, 29-40. [CrossRef]

50. Bastarianto, F.F.; Irawan, M.Z.; Choudhury, C.; Palma, D.; Muthohar, I. A Tour-Based Mode Choice Model for Commuters in Indonesia. Sustainability 2019, 11, 788. [CrossRef]

51. Samranjit, W. Travel Modal Choice from Bangkok to Chiang Mai, in Faculty of Economics; Chulalongkorn University: Bangkok, Thailand, 2005.

52. Yáñez, M.F.; Cherchi, E.; Ortúzar, J.D.D.; Heydecker, B.G. Inertia and Shock Effects on Mode Choice Panel Data: Implications of the Transantiago Implementation. In Proceedings of the 12th International Conference on Travel Behaviour Research, Jaipur, India, 13-16 December 2009.

53. Jiang, S. Modelling demand for high speed rail in Sweden: Business trips. In Transport Science; Institute for Operations Research and the Management Sciences: Halethorpe, MD, USA, 2010.

54. Yao, E.; Morikawa, T. A study of on integrated intercity travel demand model. Transp. Res. Part A Policy Pract. 2005, 39, 367-381. [CrossRef]

55. Román, C.; Carlos Martín, J.; Espino, R.; Cherchi, E.; de Dios Ortúzar, J.; Rizzi, L.I.; González, R.M.; Amador, F.J. Valuation of travel time savings for intercity travel: The Madrid-Barcelona corridor. Transp. Policy 2014, 36, 105-117. [CrossRef]

56. Börjesson, M.; Eliasson, J. Experiences from the Swedish Value of Time study. Transp. Res. Part A Policy Pract. 2014, 59, 144-158. [CrossRef]

57. Cascetta, E.; Coppola, P. An elastic demand schedule-based multimodal assignment model for the simulation of high speed rail (HSR) systems. EURO J. Transp. Logist. 2012, 1, 3-27. [CrossRef] 